\title{
ESTUDO ANTRACOLÓGICO DO COMPARTIMENTO 1, SETOR A-2008 DE MONTE MOZINHO
}

\author{
Filipe Costa $\operatorname{VaZ}^{(1)} \&$ Jõ̃o Pedro Tereso(2)
}

Resumo

Abstract

\begin{abstract}
Durante as escavações arqueológicas realizadas no Castro de Monte Mozinho, nos anos de 2008 e 2009, foram efetuadas recolhas de sedimentos com vista à realização de estudos de arqueobotânica. A presente discussão centra-se na componente antracológica das recolhas realizadas no Compartimento 1 do setor A-2008 do povoado.

Os resultados obtidos permitiram a identificação de um espectro paleoflorístico no qual se destaca a presença de castanheiro (Castanea sativa Mill.), carvalho caducifólio (Quercus tipo caducifólia), dois tipos de leguminosas, choupo (Populus L.) e pinheiro bravo (Pinus pinaster Ait.). Em segundo plano surgiram urze (Erica L.), amieiro-negro (Frangula alnus Mill.), freixo (Fraxinus L.), Prunus L. (género ao qual pertencem diversas espécies domésticas e silvestres tais como a ameixeira, o pessegueiro, o abrunheirobravo), salgueiro (Salix L.), ulmeiro (Ulmus L.) e azinheira ou sobreiro (Quercus tipo perenifólia). O número de espécies e a diversidade ecológica do conjunto analisado permitiu concluir que a recoleção de madeiras ocorreu em três formações vegetais distintas: bosques climácicos dominados por carvalhos; matos subseriais arbustivos resultantes da degradação da primeira formação; e formações ripícolas. $\mathrm{O}$ destaque de Castanea sativa L. nas amostras permitiu algumas reflexões acerca da sua integração nas dinâmicas ecológicas e económicas de época romana.
\end{abstract}

Palavras-chave: Monte Mozinho; período romano; antracologia; paleoecologia; paleoetnobotânica.

\begin{abstract}
Charcoal analysis in Monte Mozinho: a paleoecological approach to the remains from compartment 1 , sector A-2008.

During the archaeological excavations in the roman settlement of Castro de Monte Mozinho, taken place in 2008 and 2009, several soil samples were collected in order to obtain relevant archaeobotanical data. The present article focuses on the compartment 1, sector A-2008.

The results obtained allowed the identification of a paleofloristic spectre, in which stands out the presence of sweet chestnut (Castanea sativa Mill.), deciduous oak (Quercus deciduous), Leguminosae, poplar (Populus L.) and cluster pine (Pinus pinaster Ait.). In small numbers, several other species were identified, e.g. heath (Erica L.), alder buckthorn (Frangula alnus Mill.), ash (Fraxinus L.), Prunus L. (genus with a wide range of species - plum tree, cherry plum, peach, etc.), willow (Salix L.), smooth-leaved elm (Ulmus L.) and cork oak or holm oak (Quercus evergreen).

The variety of species analysed throughout the study allowed us to assume that firewood collection took place in three distinct plant formations: climacic forests of deciduous oak, subserial formations originated by its degradation and riparian vegetation. On the other hand, the relevance of Castanea sativa in these samples allowed the discussion of its integration in the regional Roman ecological and economical dynamics.
\end{abstract}

Key words: Monte Mozinho; roman period; charcoal analysis; paleoenvironment; paleoetnobotany.

\section{INTRODUÇ̃̃o}

Nas campanhas de escavação de 2008 e 2009 no Castro de Monte Mozinho, Penafiel, dirigidas pela arqueóloga Teresa Pires de Carvalho e promovidas pela Câmara Municipal de Penafiel, foram recolhidas amostras sedimentares com vista à realização de análises de Arqueobotânica.
O presente estudo decorre da investigação conducente à dissertação de Mestrado em Arqueologia do primeiro autor (VAZ 2012). Apesar da importância que o sítio arqueológico tem no panorama castrejo e romano do Norte de Portugal, esta investigação afigura-se como a primeira investigação antracológica realizada em Monte Mozinho. No entanto, será aqui apenas focada e discutida a análise paleoecológica

(1) Universidade do Porto, Faculdade de Letras, Departamento de Ciências e Técnicas do Património, Torre A, Piso 4, Via Panorâmica, s/n, 4150-564 Porto, Portugal. filipe.mcvaz@gmail.com

(2) Universidade do Porto, Faculdade de Ciências, Departamento de Biologia, Edifício FC4, Sala 1.A, Rua do Campo Alegre, s/n, 4169007, Porto, Portugal: CIBIO - Research Center in Biodiversity and Genetic Resources. jptereso@gmail.com 
resultante dos estudos antracológicos referentes ao Compartimento 1 do setor A-2008.

O objetivo foi o de juntar à difícil interpretação arqueológica do compartimento uma relevante informação respeitante à componente paisagística e etnobotânica do povoado, na valência da antracologia, depois do estudo e publicação dos resultados relativos à sua carpologia (TERESO et al. 2010, TERESO 2012).

\subsection{O sítio de Monte Mozinho}

O Castro de Monte Mozinho situa-se no concelho de Penafiel (NO Peninsular) (Fig. 1) e é partilhado administrativamente pelas freguesias de Oldrões, Galegos e Valpedre. Implantado no topo e na encosta Norte de um cabeço granítico de $408 \mathrm{~m}$ de altitude máxima, detém um alargado regime de visibilidade sobre o vale da Ribeira de Camba.
Trata-se de um povoado de fundação romana com várias fases de ocupação descontinuadas, abarcando as primeiras décadas do séc. I d.C. até ao séc. VI. Com uma área máxima estimada em cerca de 20 ha (SoEIRO 1998), está delimitado por três panos de muralha.

Escavado por Carlos Alberto Ferreira de Almeida e Teresa Soeiro entre as décadas de 70 a 90 do séc. XX, a grande maioria destas intervenções arqueológicas incidiram no topo do povoado onde se verificou a existência de uma vasta zona eminentemente habitacional organizada em torno de um espaço murado de forma elíptica (SOEIRO 1998).

Desde 2000, sob a direção de Teresa Pires de Carvalho, têm sido intervencionados novos setores de Monte Mozinho. É neste fase que se integra a escavação do setor A-2008 e o compartimento 1, aqui alvo de estudo.

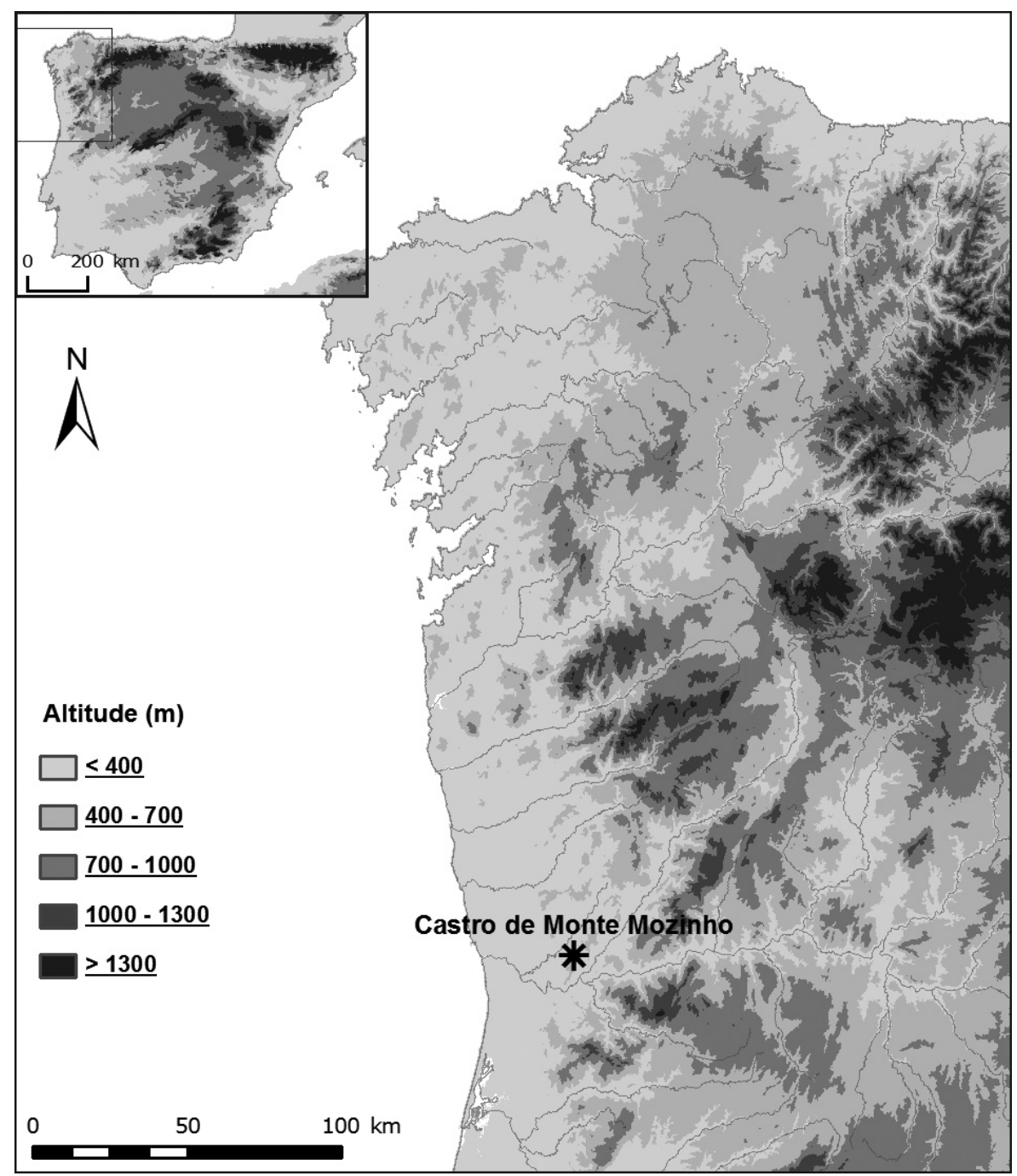

Fig. 1. Localização do Castro de Monte Mozinho no Noroeste Peninsular.

Fig. 1. Location of Castro de Monte Mozinho in Northwest Iberia. 


\subsection{O setor A-2008}

As escavações realizadas neste setor deram conta de um grande espaço onde se verificou a existência de um conjunto de estruturas e compartimentos articulados em redor de uma área tipo atrium. Trata-se no entanto de uma área que contrasta com os restantes setores postos a descoberto em monte Mozinho.
À partida, é de destacar a sua localização (Fig. 2): dentro da área intramuros do povoado mas já a meia encosta, a cerca de $100 \mathrm{~m}$ da zona superior do povoado. A prevalência de uma tipologia construtiva grosseira e pouco apurada tecnicamente diferem em muito do utilizado em plena área residencial do povoado. A escassa presença e a natureza dos materiais exumados ${ }^{1}$ em nada coincidem com um padrão resi-



Fig. 2. Localização do setor A-2008 no Castro de Monte Mozinho, a escuro.

Fig. 2. Location of sector A-2008 in the Castro de Monte Mozinho.

Refiram-se, a título de exemplo, os fragmentos de mó, dolia, encontrados nos vários compartimentos que constituem este setor (TERESO et al. 2010). 
dencial mas antes com atividades de processamento de alimentos e armazenamento de cereais. Existem também dois tipos de estruturas interpretadas como espaços de armazenagem. Trata-se de silos-fossa, encontrados no compartimento 2 e duas estruturas sub-quadrangulares, uma delas adossada ao canto Sul do compartimento 1 (Fig. 3), na qual foram encontrados cereais (Panicum miliaceum L., Setaria italica L. Beauv. e Secale cereale L.) (TERESO et al. 2010, 2012).

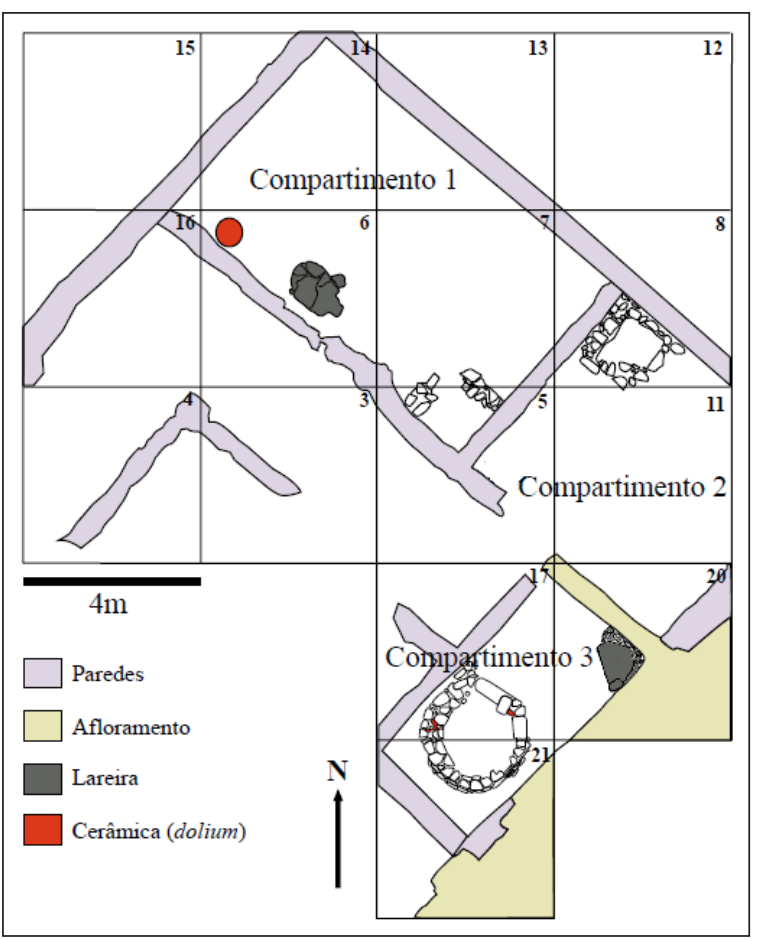

Fig. 3. Planta do setor A-2008, com destaque para o Compartimento 1.

Fig. 3. Detail of sector A-2008, focusing Compartment 1.

\section{Materiais e Métodos}

No decorrer das campanhas de escavação de 2008 e 2009 no setor A-2008 do Monte Mozinho foram realizadas recolhas de sedimentos para análise arqueobotânica. A impossibilidade de processar as amostras no local obrigou ao acondicionamento dos sedimentos para posterior processamento e estudo no Laboratório de Botânica da Faculdade de Ciências da Universidade do Porto. A incontornável necessidade deste procedimento constituiu uma relevante condicionante ao volume e quantidade das amostras recolhidas. Como tal, optou-se pela recolha de amostras ocasionais, i.e., amostragem localizada (BUXó 1990, 1997; BADAL et al. 2003; CARRÍON 2003; ESPINO 2004; TERESO 2007) cobrindo, ainda assim, grande parte da área escavada e os níveis estratigráficos mais relevantes, ou seja, os níveis de utilização e abandono das estruturas, essenciais para uma fidedigna compreensão da realidade paleobotânica do referido compartimento 1. Não foram amostrados os níveis sedimentares superficiais, posteriores ao derrube das estruturas arqueológicas.

O contexto arqueológico amostrado no compartimento 1 foi interpretado como sendo o resultado do último momento de ocupação e abandono/destruição da área. Assim, não obstante serem várias as Unidades Estratigráficas (UE) amostradas (Tabela 1), todas elas traduzem momentos sequenciais de uma única fase de ocupação assim como de um lento declínio das estruturas construídas, suscitando deste modo diferenças de cariz estratigráfico com expressão vertical e horizontal (Fig. 4). Torna-se assim crível que as amostras estudadas se relacionam, na sua maioria, com a estrutura de combustão (Fig. 5) identificada no compartimento embora seja possível a conexão de algumas com outros elementos nas imediações.

Tabela 1. Contextos e especificidades das amostras do Compartimento 1.

Quad. - Quadrado, Vol. - Volume em litros.

Table 1. Details of the samples collected in Compartment 1.

Quad. - Square, Vol. - Volume in litres

\begin{tabular}{|c|c|c|c|c|}
\hline Amostra & $\mathbf{U E}$ & Quad. & Vol. & Descrição \\
\hline 08.4 & 55 & \multirow{4}{*}{6} & 6,1 & Tonalidade cinzenta amarelada, envolvendo o dolium. \\
\hline 08.6 & \multirow{2}{*}{17} & & 6,7 & \multirow{2}{*}{ Nível de incineração. } \\
\hline 08.17 & & & 6,5 & \\
\hline 08.21 & 49 & & 10 & $\begin{array}{l}\text { Nível em tegulae de grão fino, pouco compactado e de } \\
\text { cor negra, adjacente à estrutura de combustão pétrea. }\end{array}$ \\
\hline 08.23 & \multirow{2}{*}{52} & \multirow{3}{*}{7} & 7 & \multirow{2}{*}{$\begin{array}{l}\text { Derrube de tegulae equivalente à UE } 49 \text {. Tonalidade negra } \\
\text { de grão fino a médio, inclusões de cascalho miúdo. }\end{array}$} \\
\hline 08.35 & & & 8 & \\
\hline 08.41 & \multirow{2}{*}{82} & & 7 & \multirow{2}{*}{$\begin{array}{l}\text { Nível de cor negra, com vestígios de incineração. Coberto } \\
\text { pela UE } 52 \text {. }\end{array}$} \\
\hline 09.66 & & 14 & 3 & \\
\hline
\end{tabular}




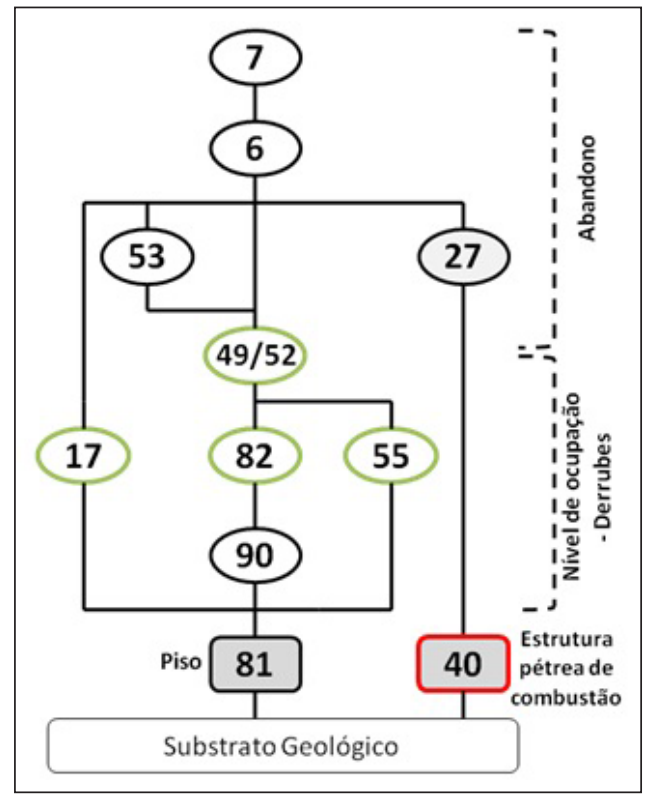

Fig. 4. Matriz de Harris correspondente às UE amostradas no Compartimento 1.

Fig. 4. Harris matrix regarding the sampled UE from compartment 1.
Esta estrutura de combustão trata-se de uma laje de granito alongada que terá servido de base de lareira, como atesta a extensa alteração térmica (rubefação) da sua superfície.

Foi obtida uma datação de radiocarbono para este momento de abandono, nomeadamente a partir de grãos de centeio recolhidos na estrutura sub-quadrangular deste compartimento 1. A datação aponta, com maior probabilidade, para um momento dentro do século III ou início do século IV (TERESO 2012) (Tabela 2).

Os sedimentos recolhidos foram processados por flutuação manual simples com recurso a malhas de crivo de $2 \mathrm{~mm}, 1 \mathrm{~mm}$ e $0,5 \mathrm{~mm}$. O conteúdo flutuado foi posteriormente seco em estufa a uma temperatura de $30^{\circ}$. Os carvões de maior dimensão (recolhidos na malha de $2 \mathrm{~mm}$ ) foram seccionados manualmente de forma a obter as 3 secções de diagnóstico: transversal, tangencial e radial. Estes segmentos foram depois observados com recurso a um microscópio de luz refletida.

Tendo em conta a especificidade dos contextos amostrados em Monte Mozinho - todas as amos-

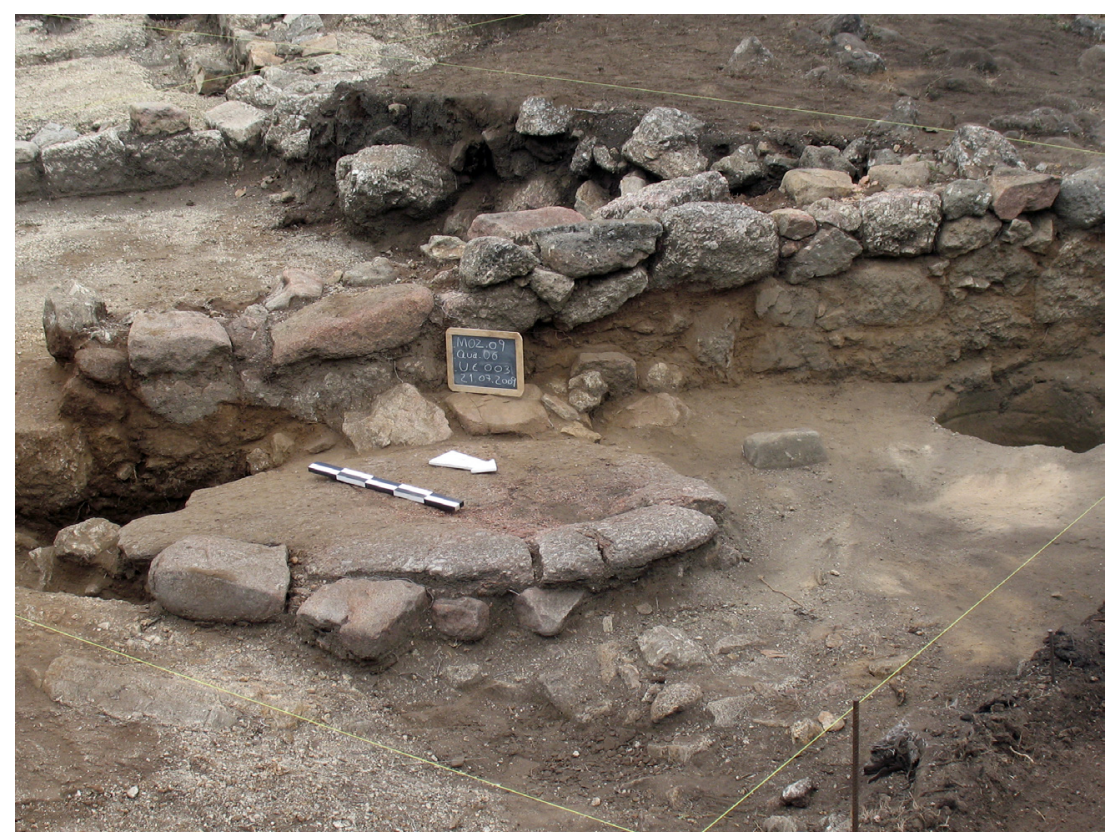

Fig. 5. Estrutura de combustão no Compartimento 1, durante escavação.

Fig. 5. Combustion structure in compartment 1 , during excavation.

Tabela 2. Resultados da datação por radiocarbono.

Table 2. Radiocarbon dating results.

\begin{tabular}{|l|l|l|l|l|}
\hline Código & Amostra & 14C yr BP & Calibração 1 Sigma & Calibração 2 Sigma \\
\hline \multirow{2}{*}{ Beta-309441 } & \multirow{2}{*}{ Grãos de Secale cereale } & \multirow{2}{*}{$1770 \pm 30$} & {$[\mathrm{cal} A D$ 228: cal AD 262] 0,429322 } & {$[$ cal AD 137: cal AD 202] 0,119654 } \\
\cline { 4 - 6 } & & {$[\mathrm{cal} A D$ 278: cal AD 329] 0,570678 } & {$[\mathrm{cal} A D$ 205: cal AD 345] 0,880346 } \\
\hline
\end{tabular}


tras foram recolhidas em contextos concentrados, usualmente os menos biodiversos (FIGUEIRAL 1994) - optou-se por uma estratégia que permitisse adequar o tempo dispensado à realização do estudo ao contexto de origem e ao volume das amostras. Estabeleceu-se previamente que seria analisado um número mínimo de 150 carvões por cada amostra. Se no intervalo entre os 100 e os 150 carvões surgisse um novo morfotipo, seriam analisados mais 50 , repetindo-se o procedimento sucessivamente. Ainda assim, algumas amostras não continham o número mínimo de fragmentos (os referidos 150), tendose efetuado um estudo integral dos fragmentos de carvões com dimensão superior a $2 \mathrm{~mm}$. Apesar deste número, a quantidade total de carvões analisados por UE é significativamente maior do que os 150 fragmentos previamente definidos pois são recorrentes os casos de amostras que provêm de uma mesma UE.

Neste estudo foram usados diversos atlas gerais de anatomia de madeiras (SCHWEINGRUBER 1990; VERNET et al. 2001). Não obstante, verificaramse algumas dificuldades de diagnóstico, algumas prendendo-se com o mau estado de preservação de alguns elementos de identificação em determinados fragmentos de carvão. Tratando-se sempre de Angiospérmicas, limitou-se o diagnóstico à distinção entre Dicotiledóneas e Monocotiledóneas. Porém, noutros casos, a dificuldade de diagnóstico resulta da própria anatomia dos géneros ou famílias incluídos nos tipos morfológicos identificados, nomeadamente, as leguminosas (Leguminosae), Ericaceae, Populus e Salix, Prunus, Fraxinus e ainda Quercus:

- foi possível discernir dois tipos distintos de leguminosas mas a similitude verificada na anatomia das madeiras das diversas espécies e géneros desta numerosa família - assim como a variabilidade existente em cada espécie - não permitiu estabelecer uma correspondência entre os diferentes tipos morfológicos e determinadas espécies ou grupos de espécies;

- também no que respeita ao género Erica existe alguma sobreposição dos caracteres anatómicos de diferentes espécies, embora estejam já definidos tipos morfológicos (TERESO 2007, baseados no trabalho de QUEIROZ \& van der BURGH 1989). Nas amostras estudadas não foi possível ir além do género;

- a diferenciação entre os géneros Populus e Salix através da anatomia das suas madeiras é uma tarefa complicada (SCHWEINGRUBER 1990). A distinção entre estes dois elementos da família das Salicaceae faz-se através da identificação na secção radial do carácter heterocelular (no caso de Salix) ou homocelular (no caso de Populus) dos raios. Como nota F. H. Schweingruber (1990), em situações ocasionais a madeira de Salix não apresenta a fiada marginal de células eretas que confere heterogeneidade aos seus raios, impossibilitando a sua distinção face a Populus. Por outro lado, segundo o mesmo autor, quando os raios de Populus apresentam células quadradas, torna-se difícil a sua distinção face a Salix;

- no caso do género Fraxinus, a diferenciação ao nível das espécies, apesar de difícil, fazse através da maior presença de parênquima paratraqueal vasicêntrico nos poros do lenho final do Fraxinus angustifólia relativamente a Fraxinus excelsior (SCHWEINGRUBER 1990). No entanto, esta é uma particularidade que não foi possível definir com segurança na população amostrada, tendo-se mantido a designação ao nível do género;

- o género Prunus inclui um conjunto grande de espécies, algumas silvestres outras cultivadas. Embora existam critérios para a sua distinção (SCHWEINGRUBER 1990; VERNET et al. 2001), é notória a sobreposição de caracteres anatómicos das diferentes espécies, sendo por isso comum na bibliografia da especialidade a identificação ao nível do género;

- a identificação de espécies do género Quercus é usualmente tida como difícil ou até impossível (SCHWEINGRUBER 1990), salvo no caso concreto de alguns elementos característicos de Quercus suber. Embora alguns autores apontem alguns critérios (FIGUEIRAL 1990; VERNET et al. 2001; QUEIROZ \& van LEEWARDEN 2003; ESPINO 2004; TERESO 2009), o seu valor taxonómico terá que ser averiguado através de estudos mais detalhados. Como tal, encontra-se generalizado na bibliografia da especialidade o uso de dois morfotipos que agrupam, por um lado, as espécies de folha persistente (Quercus perenifólia), e por outro, as de folha caduca (Quercus caducifólia).

As designações botânicas empregues devem ser encaradas como tipos morfológicos (= tipos anatómicos), ou morfotipos, com os quais se estabelece uma relação de proximidade entre as características anatómicas observadas nos fragmentos de carvões analisados e aquelas que caracterizam determinada espécie ou conjunto de espécies. Cada tipo morfológico é designado pela(s) espécie(s), género(s) ou família a que se assemelha mais. Assim, os tipos morfológicos têm efetivamente um valor taxonómico, ainda que a sua interpretação deva ser efetuada com cautela. 


\section{Resultados}

Os resultados provenientes das oito amostras recolhidas em cinco diferentes UE (Tabela 3) deste compartimento acentuam o carácter concentrado do seu contexto de recolha.

O morfotipo identificado que mais se destaca é Castanea sativa (castanheiro), sendo o mais numeroso em quase todas as UE. Segue-se-lhe em número Pinus pinaster (pinheiro-bravo), Quercus caducifólia (carvalho de folha caduca) (Fig. 6), Leguminosae e Populus sp. (choupo). Com uma presença meramente ocasional, não ultrapassando os dez fragmentos, surgem outros morfotipos: Erica sp. (urze), Frangula alnus (amieiro-negro), Fraxinus sp. (freixo), Prunus sp. (género ao qual pertencem diversas árvores e arbustos, tais como a ameixeira, o pessegueiro, o abrunheiro-bravo, entre outros), Salix sp. (salgueiro), Ulmus sp. (ulmeiro) e Quercus perenifólia (grupo no qual se incluem a azinheira, o sobreiro e o carrasco).

Uma das amostras recolhidas na UE 82 apresenta uma composição antracológica distinta das restantes. Distinta, inclusive, de uma outra amostra recolhida na mesma UE, mas num quadrado diferente e afastado (Tabela 3). A principal diferença entre esta amostra e as restantes reside na abundância e predomínio de carvões de Pinus pinaster (pinheiro-bravo),

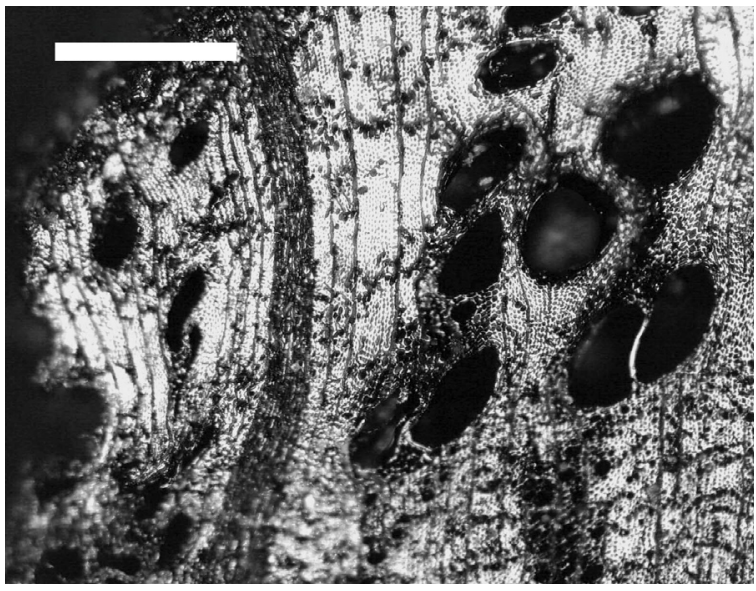

Fig. 6. Secção transversal de fragmento de Quercus caducifólia. Escala: $200 \mu \mathrm{m}$.

Fig. 6. Transverse section of a deciduous Quercus charcoal fragment. Scale: $200 \mu \mathrm{m}$.

já que se trata da única ocorrência de carvões de pinheiro em todo o compartimento. Por outro lado, são ocasionais os fragmentos de Castanea sativa, quando este é o morfotipo mais numeroso no compartimento e o mais numeroso em cada uma das restantes amostras. Registam-se ainda presenças assinaláveis de Leguminosae, para além de Populus sp. (choupo). A originalidade desta amostra sugere

Tabela 3. Morfotipos e número de fragmentos por UE.

Table 3. Morphotypes and number of fragments for each Unit of Stratification (UE) sampled.

\begin{tabular}{|c|c|c|c|c|c|c|c|}
\hline \multirow{3}{*}{$\begin{array}{l}\text { Quadrado } \\
\text { Morfotipos } \\
\text { Castanea sativa }\end{array}$} & \multicolumn{3}{|c|}{6} & \multicolumn{2}{|c|}{7} & 14 & \multirow{3}{*}{$\begin{array}{c}\text { Tota } \\
570\end{array}$} \\
\hline & 55 & 17 & 49 & 52 & \multicolumn{2}{|c|}{82} & \\
\hline & 104 & 95 & 131 & 170 & 65 & 5 & \\
\hline Erica $\mathrm{sp}$. & & & & & & 3 & 3 \\
\hline Fagaceae & & & & & 2 & & 2 \\
\hline Frangula alnus & & & & & 1 & & 1 \\
\hline Fraxinus sp. & & 1 & & 1 & 1 & & 3 \\
\hline Leguminosae & 5 & 13 & & 9 & 14 & 26 & 67 \\
\hline Pinus pinaster & & & & & & 83 & 83 \\
\hline Populus sp. & & 8 & 2 & 4 & 33 & 11 & 58 \\
\hline Prunus sp. & & 5 & & & & & 5 \\
\hline Quercus caducifólia & 6 & 62 & 2 & 1 & 5 & 1 & 77 \\
\hline Quercus perenifólia & 1 & 1 & & & & & 2 \\
\hline Salix sp. & 1 & 3 & 1 & & & & 5 \\
\hline Ulmus sp. & & 8 & & & & & 8 \\
\hline Dicotiledónea & 16 & 19 & 14 & 16 & 29 & 21 & 115 \\
\hline Monocotiledónea & & 15 & & & & & 15 \\
\hline Indeterminado & & 2 & & & & & 2 \\
\hline Total & 133 & 232 & 150 & 201 & 150 & 150 & 1016 \\
\hline
\end{tabular}


que a concentração de carvões resulta de um momento de combustão distinto daquele ou daqueles representados pelas restantes. Resta compreender se esse episódio de combustão ocorreu no local onde foi realizada a recolha ou se esta concentração de carvões resulta da limpeza da estrutura de combustão existente no compartimento (a laje que foi utilizada como base de lareira). A distância face a esta estrutura - a amostra em questão foi recolhida perto do canto Oeste do compartimento - torna mais provável que o episódio de combustão tenha ocorrido no local onde se recolheu a amostra. A existência de um dolium com o bordo ao nível do piso entre este canto e a base de lareira aponta no mesmo sentido. Note-se que, ao contrário desta, as restantes amostras estudadas, inclusive uma amostra da mesma UE 82, foram recolhidas em torno da base de lareira.

\section{Discussão e Conclusões}

O panorama paleoflorístico identificado, apesar de reduzido, remete para que a recolha de combustível lenhoso tenha tido lugar em várias formações vegetais distintas. Por comparação com a ecologia atual das espécies que se encontram incluídas nos morfotipos identificados, pressupõe-se que a recolha de madeira para utilização quotidiana em estruturas de combustão ocorreu em formações ripícolas, carvalhais e formações arbustivas (formações subseriais dos carvalhais da região). No entanto há que salientar que muitas das espécies identificadas podem enquadrar-se em mais do que uma destas formações.

Espécies como o freixo, o salgueiro, o ulmeiro, o amieiro e o choupo, exigentes em humidade edáfica, encontram-se prioritariamente em formações ripícolas, ladeando ribeiros e rios (LOURENÇO et al. 2008; FigueIRAL 1990), tal como sucede atualmente nas imediações do Castro, nomeadamente ao longo da Ribeira da Camba, Rio Cavalum e Rio Sousa (LOURENÇO et al. 2008), onde também ocorre com alguma frequência o carvalho-alvarinho. Não é possível, com os dados actuais, compreender a verdadeira extensão que estas formações ripícolas tinham na paisagem em época romana, no entanto, os dados polínicos existentes para o Noroeste peninsular atestam que este período continuou uma forte tendência de desflorestação que se iniciou na Idade do Bronze (MUÑOz SOBRINO et al.1997; RAMIL REGO et al, 1998). Acrescente-se que os dados carpológicos de Monte Mozinho atestam uma agricultura bem desenvolvida (TERESO 2012), sendo pouco provável que não tivesse uma forte incidência sobre os terrenos próximos das linhas de água, pela sua fertilidade e, naturalmente, pela abundância de água, particularmente importante para o cultivo de algumas espécies identificadas neste sítio arqueológico (e.g. o milho-miúdo e o milho-painço). Como tal, não é plausível que as florestas ribeirinhas estivessem muito desenvolvidas, sendo mais provável a existência de galerias nas áreas onde o vale apresenta uma perfil aberto e, eventualmente, de bosquetes nas áreas de mais difícil acesso.

As formações dominadas pelo carvalho parecem estar também em evidência, quer pelo número de espécies identificadas neste estudo que poderão ter feito parte da sua composição, quer pelo elevado número de carvões do género Quercus. Tendo em conta a ecologia actual da região onde se insere Monte Mozinho (LOURENÇO et al. 2008; BARBOSA 2009) e a altimetria do sítio e da sua envolvente (não ultrapassa os $450 \mathrm{~m}$ ), é provável que os carvões de carvalho caducifólia identificados correspondam a Quercus robur.

Considerando a amplitude ecológica das espécies incluídas nos tipos morfológicos identificados no estudo antracológico, várias destas poderão ter feito parte da composição dos carvalhais do período em estudo, nomeadamente o pinheiro bravo, o freixo e o próprio castanheiro. De ressalvar neste caso o facto de muitas vezes esta formação vegetal se encontrar em contacto com formações ripícolas. No que respeita, à eventual extensão das florestas climácicas, a reflexão efetuada em relação à vegetação ripícola aplica-se também neste caso.

A reiterada existência de carvões de Leguminosae, que deverão traduzir a presença de giestas, tojos e/ou codessos (em suma, espécies da tribo Genisteae), assim como de carvões de urze (Erica spp.), indica com alguma certeza um contexto ecológico de matos resultantes da degradação da floresta climácica, em especial do carvalhal, eventualmente decorrente de ação antrópica. Nos diagramas polínicos do noroeste peninsular, o declínio de pólen arbóreo ocorre usualmente em paralelo com o aumento da presença de pólen de Erica e/ou Poaceae, consoante a região (MUÑOZ SOBRINO et al. 1997; RAMIL REGO et al. 1998, 2011; DeSPRAT et al. 2003). Existe, no entanto, uma clara sub-representação das leguminosas nos diagramas polínicos, resultante da sua entomofilia assim como da fraca produção polínica de algumas espécies desta família (FIGUEIRAL \& BETTENCOURT 2004). Neste contexto, os estudos antracológicos são uma ferramenta importante para colmatar a imagem paleoecológica fornecida pelos dados polínicos.

A presença de Castanea sativa (castanheiro) é particularmente relevante tendo em conta as pro- 
blemáticas ligadas a esta espécie. A relevância de Monte Mozinho, neste aspeto, advém também da forte presença que a espécie tem no espectro antracológico do sítio, contrastando com os restantes jazidas do Norte de Portugal onde se encontraram fragmentos de Castanea sativa e onde esta espécie surge de forma residual (FIGUEIRAL 1990). O carácter autóctone deste membro da família das Fagaceae é ainda hoje discutido. Embora alguns autores sugiram o seu carácter alóctone, apontando para uma introdução no Noroeste da Península Ibérica em época romana, ou anterior, com objetivos alimentares e de produção de madeira (AGUIAR 2000), vários estudos palinológicos (MUÑOZ SOBRINO et al. 1997; RAMIL REGO et al. 1998, 2011; DESPRAT et al. 2003) demonstram que o castanheiro é uma espécie nativa desta região, tendo sobrevivido à última glaciação em refúgios, assumindo um papel secundário nas florestas caducifólias da zona até à sua expansão por mão humana.

Já no respeitante ao seu eventual cultivo, duas perspetivas também se contrapõem. As hipóteses lançadas em vários estudos que relacionam o aumento dos indicadores polínicos de Castanea sativa com eventuais cultivos e explorações com origem pré-romana ou romana (DESPRAT et al. 2003; BRIÓN 2010) são descartadas por outros trabalhos que apontam cultivos efetivos do castanheiro apenas a partir da Alta Idade Média (MUÑOz SoBRINO et al. 2007). Relativamente a esta questão, importa sublinhar que em Monte Mozinho, para além de existir madeira desta espécie, como verificado neste estudo, foi recolhida uma castanha carbonizada no compartimento 3 (contíguo ao 2) (Fig. 3) do setor A-2008. Teresa Soeiro (2005) refere também a presença deste fruto carbonizado nos setores do topo do Castro, recolhidos no decurso das escavações ocorridas durantes as últimas décadas do séc. XX. Não obstante estes dados, considerando o castanheiro uma espécie autóctone, é arriscado concluir que a existência de Castanea sativa neste sítio arqueológico se deve ao cultivo com fins de aproveitamento da madeira, como combustível e material de construção, e/ou do seu fruto para fins alimentares. $\mathrm{Na}$ verdade, são escassas as castanhas identificadas, até agora, em Monte Mozinho pelo que se desconhece que importância este fruto teria nas dietas e economia locais. Será necessária a continuação destes estudos, alargados a novos locais e diferentes cronologias de ocupação, para se poder sugerir esta prática de forma segura em Monte Mozinho. A confirmar-se o cultivo de castanheiro, tratar-se-á de um dado de extrema relevância para a caracterização paleoeconómica das populações romanas da região.

A identificação de fragmentos de Prunus levan- ta questões semelhantes às do castanheiro, nomeadamente ao nível de um seu potencial cultivo. No entanto, a escassez de fragmentos juntamente com dificuldades de identificação ao nível da espécie num género já de si muito biodiverso e que inclui espécies cultivadas e silvestres, invalidam o aprofundamento desta questão.

Esta investigação não permite inferir acerca da preservação e extensão das formações vegetais que se encontravam nas proximidades do povoado. Estudos palinológicos realizados no noroeste peninsular sugerem que, apesar de alguns diagramas polínicos registarem uma ligeira recuperação dos ecossistemas florestais durante o Baixo-Império, de um modo geral, o período a que se referem as amostras estudadas enquadra-se numa fase mais ampla de grandes ações de desflorestação, que tiveram início na primeira metade do II milénio BC (FIGUEIRAL 1996; MUÑOz SOBRINO et al. 1997; RAMIL REGO et al. 1998, 2011; DESPRAT et al. 2003). Neste sentido, e como foi já referido, é pouco provável que existissem florestas ripícolas ou carvalhais bem desenvolvidos perto de um povoado da dimensão de Monte Mozinho, no contexto do povoamento romano da região.

O presente estudo cumpriu o objetivo de, uma vez mais, afirmar não só o potencial mas também a necessidade da realização de estudos de arqueobotânica, nomeadamente de carpologia e antracologia, no percurso de qualquer investigação arqueológica. Fica claro, no entanto, a necessidade de dar seguimento às investigações nesta disciplina não apenas no Castro de Monte Mozinho - desta vez aplicadas a novas áreas do povoado - mas também a outros sítios congéneres do Norte de Portugal, já que são ainda, e infelizmente, escassos na investigação arqueológica portuguesa, quando comparado com o volume de trabalhos arqueológicos verificados no país nas últimas duas décadas.

\section{AgRadecimentos}

Agradece-se ao Prof. Doutor Fernando de Noronha a autorização da utilização do espaço e equipamentos usados no decorrer desta investigação, à Dr. Teresa Pires de Carvalho pela incansável disponibilidade durante as escavações em Monte Mozinho, à Prof. ${ }^{a}$ Doutora Teresa Soeiro pelos esclarecimentos e conselhos sobre o mesmo sítio, ao Prof. Doutor Sérgio Monteiro-Rodrigues pelos constantes pareceres e interessado acompanhamento durante todo o processo de investigação e, finalmente, aos dois revisores anónimos que contribuíram para a clarificação de alguns pontos do presente artigo. 


\section{BIBLIOGRAFIA}

Aguiar, C. 2000. Flora e vegetação da Serra de Nogueira e do Parque Natural de Montesinho. Tese de Doutoramento. Universidade Técnica de Lisboa, Lisboa.

Badal, E.; Carrión, Y,; Rivera, D. \& Uzquiano, P. 2003. La Arqueobotanica en cuevas y abrigos: objectivos y métodos de muestreo. In R. BUXÓ \& R. PIQUÉ (coord.), La recogida de muestras en arqueobotanica: objectivos y propuestas metodológicas. La gestion de los recuross vegetales u la transformacion del paopaisaje en el Mediterraneeo ocidental. Barcelona: Museo d'Arqueologia de Catalunya: 17-27.

BARBosA, S.R. 2009. Viabilidade ecológica e socioeconómica da exploração sustentável de cogumelos silvestres nos espaços florestais do Baixo Tâmega. Tese de Mestrado. Universidade do Porto, Porto.

BRIÓN, A.T. 2010. Wild fruits, domesticated fruits. Archeobotanical remains in Roman saltworks at O Areal, Vigo (Galicia, Spain). In C. DELhom, I. ThÉRY-PARISOT \& S. ThiÉBAUlT (coord.), Des hommes et des plantes. Exploitation du milieu et gestion des ressources végétales de la préhistoire à nos jours. XXXe rencontres internationales d'archéologie et d'histoire d'Antibes Sous. Antibes: Éditions APDCA: 199-207.

BuXÓ, R. 1990. Metodología y técnicas para la recuperación de restos vegetales (en especial referencia a semillas y frutos) en yacimientos arqueológicos. In E. CARBOnell, A. CABAÑas, M. Guilbaud \& R. SAla (coords.), Cahier Noir 5. Girona: Ajuntament de Girona: 3-63.

BuXÓ, R. 1997. Arqueologia de las plantas. Barcelona: Crítica.

CARríon, Y. 2003. Afinidades y diferencias de las secuencias antracológicas en las vertientes mediterranea e atlantica de la peninsula Iberica. Tesis Doctoral. Universidad de Valencia, Valencia.

Desprat, S.; GoÑI, M.F.S. \& LOUTRE, M.-F. 2003. Revealing climatic variability of the last three millennia in northwestern Iberia using pollen influx data. Earth and Planetary Science Letters, 213: 63-78.

ESPINO, D. 2004. La gestión del paisaje vegetal en la Prehistoria Reciente y Protohistoria en la Cuenca Media del Guadiana a partir de la Antracologia. Tesis Doctoral. Universidad de Extremadura, Badajoz.

FigueIRAL, I. 1990. Le nord-ouest du Portugal et les modifications de l'ecosysteme, du Bronze final à l'époque romaine, d'aprés l'anthracoanalyse de sites archéologiques. These Doctorat. Université des Sciences et Techniques du Languedoc, Montpellier.

Figueiral, I. 1994. A Antracologia em Portugal: Progressos e Perspectivas. Trabalhos de Antropologia e Etnologia, 34: 429-447.

FigUEIRAL, I. 1996. Wood resources in north-west Portugal: their availability and use from the late Bronze Age to the Roman period. Vegetation History and Archaeobotany: 121-129.

Figueiral, I. \& Bettencourt, A. 2004. Middle/Late Bronze Age plant communities and their exploitation in the Cavado Basin (NW Portugal) as shown by charcoal analysis: the significance and co-occurrence of Quercus (deciduous) Fabaceae. Vegetation History and Archaeobotany, 13: 219-232.
Lourenço, A.; Tavares, A.S.; Couto, H.; Rocha, I.; CAldas, F.B.; Gomes, N. \& Alves, P. 2008. Terra do Sousa, Natureza Rural. Felgueiras: Ader-Sousa, Publigraff.

Muñoz Sobrino, C.; RAmil-Rego, P. \& Guitián, M.R. 1997. Upland vegetation in the north-west Iberian peninsula after the last glaciation: forest history and deforestation dynamics. Vegetation History and Archaeobotany, 6: 215-233.

Muñoz Sobrino, C.; García-Gil S. \& Diez, J.B. 2007. Palynological characterization of gassy sediments in the inner part of Ría de Vigo (NW Spain). New chronological and environmental data. Geo-Marine Letters, 27: 289-302.

QueIROZ, P. \& van der BuRGH, J. 1989. Wood Anatomy of Iberian Ericales. Revista de Biologia, 14: 95-134.

Queiroz, P. \& van LeEuwaArden, W. 2003. Estudos de Arqueobotânica em quatro estações pré-históricas do Parque Arqueológico do Vale do Côa. Revista Portuguesa de Arqueologia, 6: 275-291.

RAMIL REgo, P.; MuÑOZ-Sobrino, C.; RodríGUEZ-Guitián, M.; Gómez-OrEllanA, L. 1998. Differences in the vegetation of the North Iberian Peninsula during the last 16,000 years. Plant Ecology, 138: 41-62.

Ramil Rego, P.; Gómez Orellana, L.; Muñoz Sobrino, C. \& TERESO, J.P. 2011. Dinâmica natural e transformação antrópica das Florestas do noroeste ibérico. In J.P. TERESO, J.P. Honrado, A.T. Pinto \& F.C. Rego (coord.), Florestas do Norte de Portugal: História, Ecologia e Desafios de Gestão. InBio - Rede de Investigação em Biodiversidade e Biologia Evolutiva. E-book. Porto.

SoEIRO, T. 1998. Monte Mozinho. 25 anos de trabalhos arqueológicos. Cadernos do Museu, 2: 11-28.

Soeiro, T. 2005. Monte Mozinho - Sítio Arqueológico. Penafiel: Museu Municipal de Penafiel.

SCHWEINGRUBER, F.H. 1990. Anatomy of European woods. Berna: Paul Haupt and Stuttgart Publishers.

Tereso, J. 2007. Paleoetnobotânica do povoado romano da Terronha de Pinhovelo (NE transmontano). Tese de Mestrado. Universidade do Porto, Porto.

TERESO, J. 2009. Estudo paleoetnobotânico das estruturas romanas da Terronha de Pinhovelo (Macedo de Cavaleiros). Cadernos Terras Quentes, 6: 81-90.

TERESO, J. 2012. Environmental change, agricultural development and social trends in NW Iberia from the Late Prehistory to the Late Antiquity. Dissertação de Doutoramento. Universidade do Porto, Porto.

Tereso, J.; Carvalho, T.P.; Almeida da Silva, R. \& RamilREgo, P. 2010. Cultivos e armazenagem em Monte Mozinho: dados preliminares. In A. Bettencourt; M. Alves \& S. Monteiro-Rodrigues (eds.), Variações Paleoambientais e evolução antrópica no Quaternário do ocidente peninsular. APEQ/CITCEM: 149-158.

VAZ, F.C. 2012. Gestão e usos de recursos vegetais no Noroeste Peninsular: a Antracologia de Monte Mozinho. Dissertação de Mestrado. Universidade do Porto, Porto.

Vernet, J-L.; Figueiral I. \& UzQuiano, P. 2001. Guide d'identification des charbons de bois préhistoriques et récents. Sud-Ouest de l'Europe: France, Péninsule ibérique et îles Canaries. Paris: CNRS Editions. 